\title{
Evaluating the cost-effectiveness of tiotropium versus salmeterol in the treatment of chronic obstructive pulmonary disease
}

This article was published in the following Dove Press journal:

ClinicoEconomics and Outcomes Research

5 March 2010

Number of times this article has been viewed

\author{
Shalini Naik \\ Khalid M Kamal \\ Patricia A Keys \\ Thomas J Mattei \\ Duquesne University School \\ of Pharmacy, Pittsburgh, PA, USA
}

Correspondence: Khalid M Kamal Assistant Professor, Department of Pharmacy Administration, Duquesne University School of Pharmacy, Pittsburgh, PA 15282, USA

Tel + | 4I 2-396-1926

Fax + | 4I2-396-5I30

Email kamalk@duq.edu
Objective: To assess the cost-effectiveness of 3 treatments (tiotropium, salmeterol, and no treatment) in patients with moderate chronic obstructive pulmonary disease (COPD).

Methods: A Markov model with a time horizon of 1 year was developed. A hypothetical cohort of 100,000 subjects with moderate COPD with mean age of 65 years, smoking history of 50 pack-years, and disease duration of 9.5 years were included in the model. The efficacy and withdrawal data were taken from published randomized clinical trials. The effectiveness measure was exacerbations avoided per patient per year. Incremental cost-effectiveness ratio (ICER) was calculated as additional cost per patient to prevent 1 exacerbation, compared with the next most expensive option. A payer's perspective was used and only direct costs were included in the study. Sensitivity analyses were conducted to test the robustness of the baseline estimates and study assumptions.

Results: The mean annual costs for the no treatment, salmeterol, and tiotropium groups were \$392.1, \$1268.7, and \$1408.6, respectively. The ICER of tiotropium compared with no treatment was \$1817.36 per exacerbation avoided, while the ICER of salmeterol compared with no treatment was $\$ 2454.48$ per exacerbation avoided. Thus, in patients with moderate COPD, tiotropium is more cost-effective than salmeterol and no treatment.

Keywords: cost-effectiveness, chronic obstructive pulmonary disease, markov model, tiotropium, salmeterol

\section{Introduction}

Chronic obstructive pulmonary disease (COPD) is a respiratory disease characterized by chronic cough, sputum production, and dyspnea which leads to restricted activity, disability, and poor quality of life (QoL). ${ }^{1-3}$ The disease is highly prevalent and is increasing worldwide. ${ }^{4}$ It has been estimated that 10 to 16 million people in the United States (US) have been diagnosed with some form of COPD and as nearly 14 to 16 million still remain undiagnosed. ${ }^{5,6} \mathrm{COPD}$ is the fourth leading cause of death after heart disease, cancer, and cerebrovascular disease and is projected to be the third leading cause of death by the year $2020 .^{3,6,7}$ It is one of the leading causes of morbidity and mortality worldwide and also imparts a substantial economic burden on individuals as well as on society. ${ }^{3}$ The total cost of COPD in the US is projected to be $\$ 49.9$ billion in 2010 , of which $\$ 29.9$ billion is attributed to direct cost (cost associated with medical and pharmacy resource utilization). ${ }^{1}$

COPD is a respiratory disease characterized by airflow limitation that is not fully reversible. The airflow limitation is progressive and associated with an abnormal inflammatory response of the lungs. COPD mainly comprises chronic 
bronchitis and emphysema. In chronic bronchitis, there is inflammation and swelling of the airway linings that lead to narrowing and obstruction of the airways. This inflammation triggers the production of mucous (sputum), which causes further obstruction of the airways. Emphysema is a condition in which the walls between the alveoli or air sacs within the lung lose their ability to stretch and recoil. The air sacs become weakened and break and the elasticity of the lung tissue is lost. Air trapping in the air sacs impairs the exchange of oxygen and carbon dioxide. In 2002, the National Health Interview Survey reported that in patients above 65 years of age, $5.4 \%$ were diagnosed with chronic bronchitis and $4.8 \%$ with emphysema. ${ }^{3,7}$

COPD is classified into 4 stages based on the level of disease severity: ${ }^{3}$

Stage 0: At risk: This stage is characterized by chronic cough and sputum production. Lung function, as measured by spirometry, is normal.

Stage I: Mild COPD: This stage is characterized by mild airflow limitation (forced expiratory volume in 1 second $\left[\mathrm{FEV}_{1}\right]$ versus forced vital capacity $[\mathrm{FVC}]<70 \%$ but $\mathrm{FEV}_{1} \geq 80 \%$ predicted) with or without cough and sputum production. At this stage, the individual may not even be aware that his or her lung function is abnormal.

Stage II: Moderate COPD: This stage is characterized by worsening airflow limitation $\left(50 \% \leq \mathrm{FEV}_{1}<80 \%\right.$ predicted $)$ and progression of symptoms, with shortness of breath. At this stage the patients typically seek medical attention because of dyspnea or disease exacerbation. There is a significant impact on patient QoL.

Stage III: Severe COPD: This stage is characterized by severe airflow limitation $\left(30 \% \leq \mathrm{FEV}_{1}<50 \%\right.$ predicted $)$ or the presence of respiratory failure or clinical signs of right heart failure.

Stage IV: Very severe COPD: At this stage, the $\mathrm{FEV}_{1}$ $<30 \%$ predicted. The individual's QoL is appreciably impaired and exacerbations may be life-threatening. In addition to the $\mathrm{FEV}_{1}$, body mass index (BMI) and dyspnea have proved useful in predicting outcomes such as survival in severe COPD.

Effective management at early stages of disease is thus crucial. Management of mild to moderate COPD involves avoidance of risk factors to prevent disease progression and use of pharmacotherapy options to control symptoms. ${ }^{8,9}$ Early identification and management can prove beneficial by avoiding a major portion of healthcare costs associated with emergency visits and hospitalizations, thereby reducing the healthcare costs considerably.
COPD is undoubtedly a very costly disease if left untreated. With the introduction of new treatment strategies in treating COPD, there is a necessity to identify the most cost-effective strategies. An effective selection from the available treatment strategies by decision-makers can be beneficial both clinically as well as an economically. However, given the dearth of information on the economic consequences of different treatment strategies used for COPD, there is a need to conduct economic analyses to optimize treatment selection and guide better decision-making.

Global Initiative for Chronic Obstructive Pulmonary Disease (GOLD) and American Thoracic Society (ATS) guidelines recommend use of bronchodilators (anticholinergics and $\beta_{2}$-agonists) as first-line therapy in treating patients with moderate COPD. ${ }^{3,6}$ The guidelines, however do not mention any specific preference between the two drug classes under bronchodilators: $\beta_{2}$-agonists and anticholinergics, to be used as first-line therapy. The long-acting bronchodilators such as $\beta_{2}$-agonists that are available by prescription in the US include salmeterol (Serevent ${ }^{\mathbb{}}$; GlaxoSmithKline), and formoterol (Foradil ${ }^{\circledR}$; Schering-Plough), and the long-acting anticholinergics include tiotropium (Spiriva ${ }^{\circledR}$; Pfizer/Boehringer Ingelheim).

Salmeterol and formoterol are administered twice daily, while tiotropium is administered just once daily. Data from randomized clinical trials have shown the clinical superiority of tiotropium, a long-acting anticholinergic, over other bronchodilators. ${ }^{10}$ However, the cost of tiotropium is much higher in comparison to salmeterol, a long-acting $\beta_{2}$-agonist. The unit cost price of tiotropium is $\$ 130.63$, while that of salmeterol is $\$ 113.47 .{ }^{11}$ Thus, it remains to be seen if tiotropium $\left(\right.$ Spiriva $^{\circledR}$ ) is cost-effective as first-line therapy in comparison to salmeterol (Serevent ${ }^{\circledR}$ ) when used over an extensive period of time. In addition, the once-a-day dosing may prove to be more convenient and provide more consistent bronchodilation than twice daily administration of salmeterol (Serevent $\left.{ }^{\circledR}\right){ }^{3,6}$ This dosing of tiotropium may also increase the likelihood of patient compliance. ${ }^{12-14}$ It is well established that noncompliance with medication therapy results in therapeutic failure and dramatic increase in healthcare use. ${ }^{12-14}$ Thus, tiotropium has benefits over salmeterol for clinical efficacy as well as dosing convenience but is an expensive treatment compared to salmeterol.

There are few studies in the literature that have estimated the cost-effectiveness of tiotropium and salmeterol. However, no economic study comparing tiotropium and salmeterol has been done from a US payer perspective. These two medications have an advantage over other medications 
used in COPD in that they are long-acting and require less frequent administration than other drugs. ${ }^{15-19}$ This study aims at developing a decision analytical model to measure the cost-effectiveness of 3 treatment strategies: tiotropium, salmeterol, and no treatment. A Markov model, a type of decision analytic model, was developed to compare the costs and effects of tiotropium, salmeterol, and no treatment. A Markov model with a 6-month time cycle and an analytical time frame of 1 year was developed. The goal was to summarize costs and outcomes of tiotropium, salmeterol, and no treatment and to identify the most cost-effective option in patients with moderate COPD.

\section{Study objectives}

The overall aim of the study was to determine if tiotropium (long-acting anticholinergic), is more cost-effective than salmeterol (long-acting beta agonist) and no treatment. The no treatment comparison group included data derived from patients on the placebo arm of clinical trials of these drugs.

The specific objectives were:

Objective 1: To develop a Markov model to assess the cost-effectiveness of tiotropium, salmeterol, and no treatment in patients with moderate COPD.

Objective 2: To develop cost-effectiveness models based on the Markov model to determine the incremental costs and consequences of tiotropium, salmeterol, and no treatment in patients with moderate COPD.

\section{Methodology}

A literature search was conducted to identify all clinical trials conducted to date for tiotropium and salmeterol (see Table 1). A Markov model was constructed using the decision analytical model technique Figure $1 .^{20}$ The Markov model was developed using Data TreeAge Pro software. ${ }^{21}$ The model evaluated the cost-effectiveness of 3 treatments: tiotropium, salmeterol, and no treatment in patients with moderate COPD. Data for tiotropium and salmeterol were derived from the respective clinical trials while the no treatment group included data derived from the patients on placebo in these clinical trials. The placebo was plain lactose capsules, administered via a dry powder inhaler device. The patients in the control/placebo/no treatment group were permitted albuterol metered-dose inhaler, inhaled steroids and oral steroids (up to the equivalent of prednisolone, 10 $\mathrm{mg}$ /day) during the baseline period and throughout the entire study, as needed to relieve symptoms. The main analytical plan was to calculate incremental cost- effectiveness ratios (ICERs).

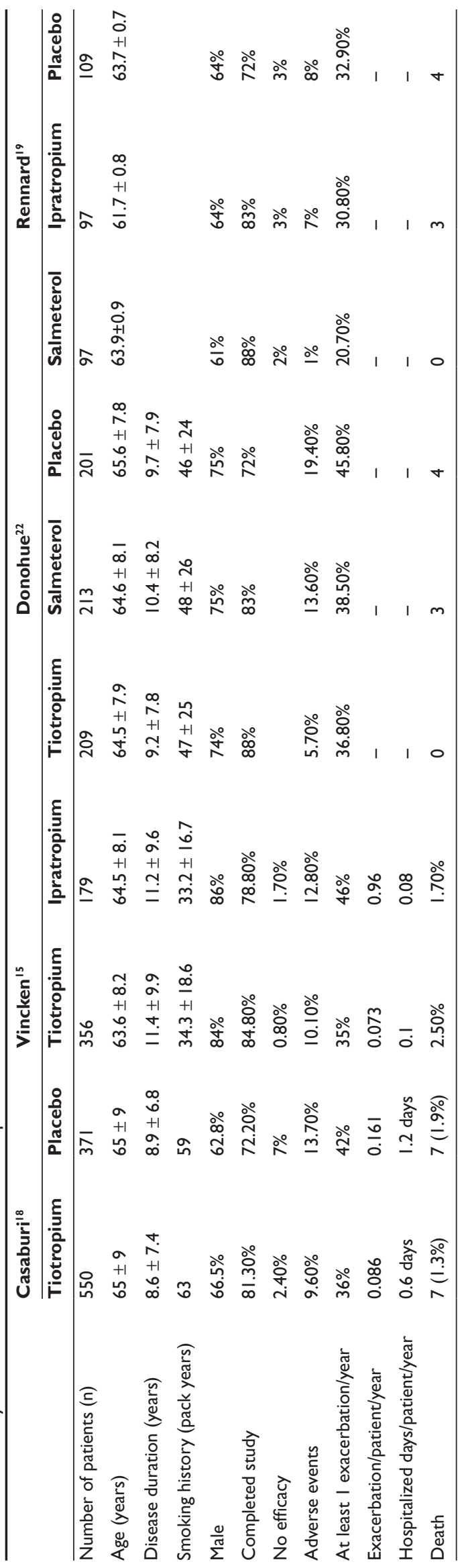




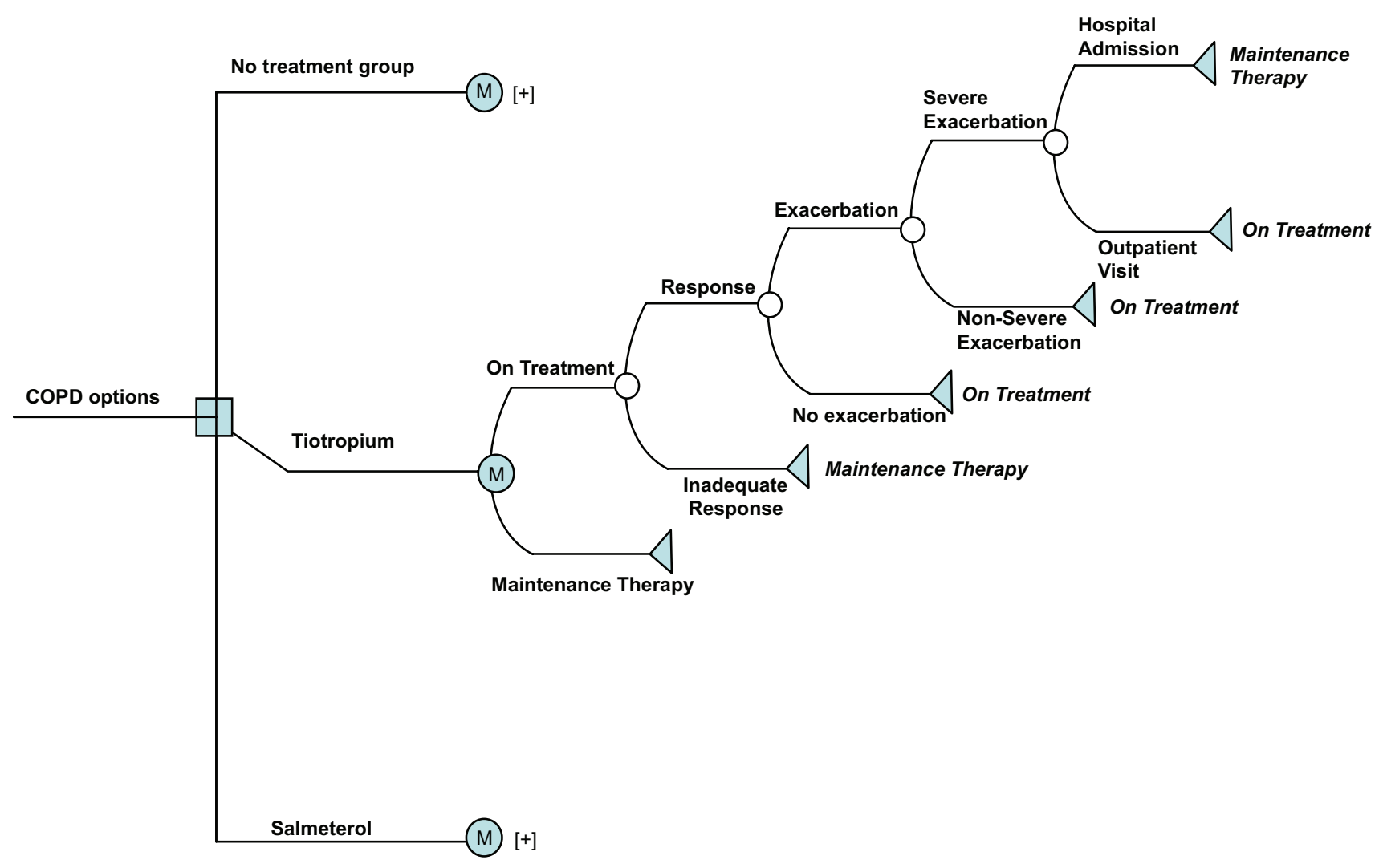

Figure I Markov model demonstrating the various Markov states.

Notes: $(+)$ indicates that the same tree is repeated for each of the arms.

The decision model comprised of two mutually exclusive Markov states: 'on treatment', and 'maintenance therapy'. The on treatment branch represents patients who continue on the treatment which they were started on (either tiotropium, salmeterol or no treatment). The maintenance therapy branch represents alternate treatment option for those patients who do not continue on treatment. The patients on each treatment arm may either be on treatment or on maintenance therapy. The patients on treatment have a chance of experiencing one of the two events: 1) they may either respond to the treatment or 2) they may show an inadequate response to treatment. An inadequate response includes patients who withdraw from treatment due to lack of medication effect, or side-effects or death. Since there is a chance of experiencing either of the two events, it is represented by a chance node. The patients with an inadequate response continue on maintenance therapy. The maintenance therapy state for this study was assumed to comprise the following: short-acting anticholinergic (ipratropium), short-acting $\beta$-agonist (albuterol), theophylline, and an inhaled steroid (fluticasone). ${ }^{15}$ These medications were selected on the basis of clinical opinion and GOLD guidelines. ${ }^{3}$ The doses and dosage frequency of these medications are:
Ipratropium: 2 puffs $(40 \mu \mathrm{g}), 4$ times a day.

Albuterol: 2 puffs $(90 \mu \mathrm{g}), 4$ times a day.

Theophylline: $400 \mu \mathrm{g}$ once a day.

Steroid (fluticasone nasal spray): $50 \mu \mathrm{g}$ twice daily.

The patients who respond to the treatment may either experience an exacerbation or no exacerbation. Those who do not experience exacerbation will continue using the same treatment. However, patients who experience exacerbation may have a severe or a nonsevere exacerbation. Nonsevere exacerbations are the ones that can be controlled by continued use of on treatment medication. Patients with nonsevere exacerbation will continue on the same treatment strategy. However, patients experiencing severe exacerbation will then be prescribed an additional steroid medication ${ }^{3}$ along with the initial treatment which the patient was on. Thus, an additional steroid medication (fluticasone) cost will be incurred by this group. Patients with severe exacerbation could either be hospitalized or may undergo outpatient treatment. Those who undergo hospitalization even after continuing the same treatment will then be switched to maintenance therapy, while those who undergo outpatient treatment will continue using the same treatment. Hospitalization costs will be incurred by patients who undergo hospitalizations 
and outpatient costs will be incurred by the patients who respond to treatment.

\section{Model characteristics \\ Patient population}

The patient population in the model was a hypothetical cohort of 100,000 male patients with a mean age of 65 years, a smoking history of at least 50 pack-years, and disease duration of at least 9.5 years. The characteristics of the hypothetical patients were selected to closely reflect the characteristics of the patient population included in the randomized clinical trials of the treatments. ${ }^{15,18,19,22}$

\section{Cycle length}

The cycle length selected for this study was 6 months, because at the time the study was conducted (2006) no long-term study had been done, and the duration of most randomized clinical trials at that time of the treatments in COPD was 6 months.

\section{Perspective}

The study was conducted from a third-party payer perspective. Thus, only direct costs of COPD were considered in the analysis. Direct costs included in the study were drug costs, hospitalization costs, monitoring costs, and physician visit costs.

\section{Analytical time frame}

Since most third-party payers are interested in cost over a period of 1 to 3 years, the ICERs of the treatments were modeled over a period of 1 year.

\section{Outcome measure}

The outcome measure considered in this study was cost per exacerbation avoided per patient per year. ICERs were calculated as additional cost per patient to prevent 1 exacerbation, compared with the next most expensive option. The uncertainty of the baseline estimates and study assumptions was tested by conducting sensitivity analyses. If the ranges for variables from literature were not available, a $\pm 20 \%$ range of the base-case estimate was used in the sensitivity analyses.

\section{Analysis}

This model was evaluated using the Monte Carlo simulation technique. Monte Carlo simulation is a computer simulation technique, which involves estimating the approximate probability of outcomes by running multiple simulations, using various random variables as inputs Monte Carlo has an advantage over cohort simulation technique in that it provides a better measure of variability associated with the parameters than with estimates in a cohort simulation. ${ }^{23,24}$ Sensitivity analysis was done for the following variables: probability of exacerbation, probability of hospitalization, probability of severe exacerbation, and compliance.

\section{Operationalizing the model}

The efficacy rates for tiotropium, salmeterol, and no treatment group were obtained from published clinical trials. The efficacy data for the no treatment group are the data obtained for placebo arms of clinical trials for tiotropium and salmeterol. ${ }^{15,18,19,22}$ For tiotropium, 3 studies were identified. In a study by Casaburi and colleagues, 18 the exacerbation rate per patient per year for tiotropium was 0.086 . Around $36 \%$ patients on tiotropium had at least 1 exacerbation per year. In a study by Vincken and colleagues, ${ }^{15}$ patients on tiotropium had 0.073 exacerbations per patient per year. Around 35\% patients on tiotropium had at least one exacerbation per year. In a study by Donohue and colleagues, ${ }^{22}$ the exacerbations per patient per year was not reported. Around $36.8 \%$ patients on tiotropium had at least 1 exacerbation per year.

For salmeterol, 2 studies were identified whose data were used in our study. In a study by Donohue and colleagues, ${ }^{22}$ $38.5 \%$ patients on salmeterol had at least 1 exacerbation per year. The exacerbation rate per patient per year was not reported. In a study by Rennard and colleagues, ${ }^{19} 20.7 \%$ patients on salmeterol showed at least 1 exacerbation per year. For the no treatment group (placebo), 3 studies were identified. In a study by Casaburi and colleagues, ${ }^{18}$ the rate of exacerbation per patient per year was found to be 0.161 . Around $42 \%$ patients on no treatment (placebo) had at least 1 exacerbation per year. In a study by Donohue and colleagues, $45.8 \%$ patients on no treatment (placebo) had at least 1 exacerbation per patient per year. In a study by Rennard, ${ }^{19} 32.9 \%$ patients on no treatment (placebo) had at least 1 exacerbation per patient per year.

\section{Data}

\section{Probabilities}

The transition of patients during each cycle from one Markov state to another state is called transition probability. These transition probabilities were derived from published randomized clinical trials of various treatments. The transition from one event to another was also taken from published literature 
Table 2 Probability values (6-month data taken from clinical trials; ranges for sensitivity analysis)

\begin{tabular}{|c|c|c|c|c|c|c|c|c|c|}
\hline & \multicolumn{3}{|c|}{ No treatment } & \multicolumn{3}{|l|}{ Salmeterol } & \multicolumn{3}{|c|}{ Tiotropium } \\
\hline & \multicolumn{3}{|c|}{ Sensitivity analysis } & \multicolumn{3}{|c|}{ Sensitivity analysis } & \multicolumn{3}{|c|}{ Sensitivity analysis } \\
\hline & $\begin{array}{l}\text { Base-case } \\
\text { value }\end{array}$ & $\begin{array}{l}\text { Low } \\
\text { value }\end{array}$ & $\begin{array}{l}\text { High } \\
\text { value }\end{array}$ & $\begin{array}{l}\text { Base-case } \\
\text { value }\end{array}$ & $\begin{array}{l}\text { Low } \\
\text { value }\end{array}$ & $\begin{array}{l}\text { High } \\
\text { value }\end{array}$ & $\begin{array}{l}\text { Base-case } \\
\text { value }\end{array}$ & $\begin{array}{l}\text { Low } \\
\text { value }\end{array}$ & $\begin{array}{l}\text { High } \\
\text { value }\end{array}$ \\
\hline Probability of exacerbation & 0.2897 & 0.1895 & 0.39 & 0.35 & 0.343 & 0.357 & 0.2424 & 0.1648 & 0.32 \\
\hline Probability of hospitalization & 0.04795 & 0.0459 & 0.05 & 0.05 & 0.049 & 0.051 & 0.0274 & 0.0247 & 0.03 \\
\hline $\begin{array}{l}\text { Probability of severe } \\
\text { exacerbation }\end{array}$ & 0.145 & 0.1 & 0.2 & 0.15215 & 0.138 & 0.167 & 0.285 & 0.112 & 0.4579 \\
\hline
\end{tabular}

(see Table 2). The probability was calculated from rates derived from clinical trials using the following formula:

$$
\mathrm{P}=\left[1-\mathrm{e}^{(-\mathrm{r})(\mathrm{t})}\right]
$$

where, $\mathrm{P}=$ probability, $\mathrm{r}=$ rate, $\mathrm{t}=$ time

\section{Costs}

Since the study assumes a third-party payer perspective, only direct costs were taken into consideration. The direct costs included drug costs, hospitalization costs, monitoring costs, and physician visits costs. The drug costs which include cost of tiotropium and salmeterol were taken from the Red book. ${ }^{11}$ Also, cost of maintenance therapy which includes an anticholinergic (ipratropium), $\beta$-agonist (albuterol), theophylline, and steroid (fluticasone) were taken from Red book. ${ }^{11}$

The laboratory test and monitoring tests included spirometry, chest X-ray, complete blood count, hepatic function profile, electrocardiogram monitoring and analysis, and sputum gram stain. These tests were identified with Current Procedural Terminology (CPT) codes and the costs were derived from Medical Insurance Reimbursement-based Maximum Allowable Charges (MACs) for the year $2006 .^{25}$ Physician visit costs as well as hospitalization costs were also derived from the same source. All costs included in the study were for the year 2006 (see Table 3). Since no old costs or future costs were included in the analysis, there was no need to inflate or discount costs in this study.

\section{Model assumptions and rationale}

Compliance is a very important aspect in determining effectiveness of a medication treatment. According to a study by Cramer and colleagues, compliance rate was highest for tiotropium compared to other bronchodilator drugs $(94 \%$ to $76 \%) .{ }^{26}$ In the present study, we assumed the compliance rate

Table 3 Cost data ${ }^{a}$ (6-month data; ranges for sensitivity analysis)

\begin{tabular}{|c|c|c|}
\hline & Unit cost (\$) & $\begin{array}{l}\text { Cost for } 6 \text { months ( } \$ \text { range } \\
\text { for sensitivity analysis) }\end{array}$ \\
\hline \multicolumn{3}{|l|}{ Laboratory tests } \\
\hline Arterial blood gas & 48.34 & $48.34(48.32-49.30)$ \\
\hline Spirometry & 59.89 & $59.89(58.69-6 \mathrm{I} .08)$ \\
\hline Chest X-ray & 50.96 & $50.96(49.94-51.97)$ \\
\hline ECG monitoring & 253.21 & $253.21(248.14-258.27)$ \\
\hline Sputum gram stain & 24.06 & $24.06(23.57-24.54)$ \\
\hline Hospitalization/day & 366.49 & \\
\hline Physician visit & 94.26 & $94.26(92.37-96.14)$ \\
\hline \multicolumn{3}{|l|}{ Drug costs } \\
\hline Tiotropium ( $18 \mu \mathrm{g}$ once daily) & 130.63 & 783.78 (768.10-799.45) \\
\hline Salmeterol ( $50 \mu g$ twice daily) & 113.40 & $680.80(667.18-694.4 I)$ \\
\hline Ipratropium ( 2 puffs of $40 \mu \mathrm{g} 4$ times a day) & 84.60 & $609.12(596.98-621.30)$ \\
\hline Albuterol ( 2 puffs of $90 \mu \mathrm{g} 4$ times a day) & 29.79 & $2 \mid 4.48$ (209.65-2।8.82) \\
\hline Theophylline (400 mg once daily) & 85.75 & $154.35(151.26-157.43)$ \\
\hline Fluticasone ( $50 \mu \mathrm{g}$ twice daily) & 50.00 & $348.00(341.04-354.96)$ \\
\hline
\end{tabular}

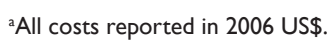


for patients on tiotropium to be $90 \%$. In a study by Holt and colleagues, it was found that the compliance rate in patients with a combination of salmeterol and fluticasone inhaler was almost $75 \% .{ }^{27}$ Since there are no studies in the literature on compliance rate with salmeterol alone; the study assumed a compliance rate with salmeterol as $75 \%$. Also, according to the literature, the overall level of compliance with use of inhaled medications in the treatment of asthma was on average found to be $50 \% .^{28}$ In this study it that the level of compliance for the no treatment group was assumed to be $50 \%$. This assumption was necessary to quantify the cost and consequences of introducing agents under real world practice. However, base-case estimates of compliance were varied in the sensitivity analysis to test their impact on the study results.

The study assumed that the hypothetical patients will not suffer from any other co-morbid conditions and hence will not consume any other medications. This assumption was necessary since it is not feasible to quantify the usage of different medications in the presence of co-morbid conditions. The study also did not take into consideration patients on nebulizers since the study population comprised of patients with moderate COPD only. Typically, patients on nebulizers are usually those who are at a more severe stage of disease or are physically limited in their ability to use devices. The study was done only for a period of 1 year and it is assumed that during this 1-year period, the disease condition of the patient remains the same and that the patients did not transition into a higher level of disease severity.

\section{Results}

\section{Base-case analysis}

A total of 100,000 hypothetical patients aged 65 years, with smoking history of 50 pack years, and disease duration of 9.5 years were sampled for the three treatments using a first-order Monte Carlo simulation. Estimated mean costs and effectiveness are reported in Table 4. The mean annual cost of treatment in no treatment group was the lowest (\$392.1), followed by salmeterol $(\$ 1,268.66)$ and highest for

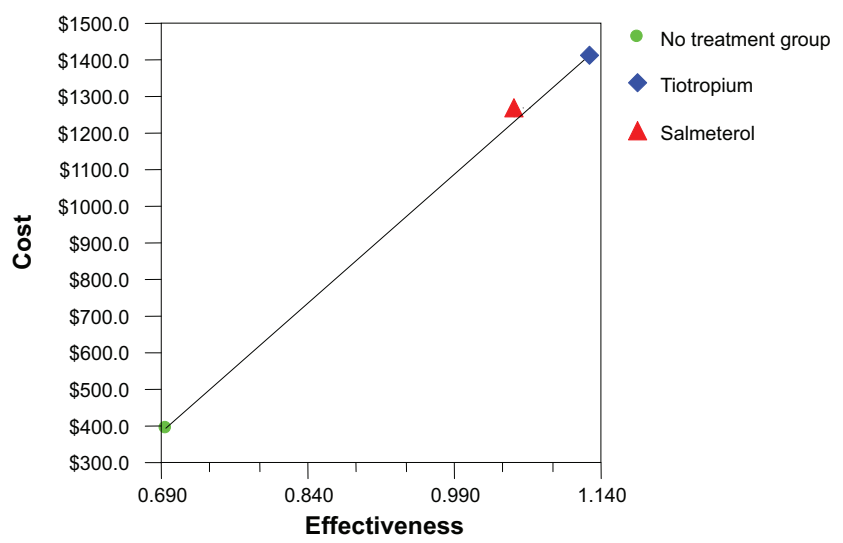

Figure 2 Costs and effectiveness of different treatments for patients with moderate COPD (cost-effectiveness analysis from Monte Carlo simulation).

Notes: The $x$-axis represents effectiveness (exacerbations avoided per patient per year) and the $y$-axis gives the direct cost in US\$.

tiotropium $(\$ 1,408.59)$. The mean effectiveness was highest for tiotropium (1.129 exacerbations avoided per patient per year) followed by salmeterol (1.052 exacerbations avoided per patient per year) and no treatment group (0.694 exacerbations avoided per patient per year). The results for direct costs are also represented graphically in Figure 2, where the x-axis represents effectiveness (exacerbations avoided per patient per year) and the y-axis gives the direct cost in dollars.

An incremental analysis was conducted to identify the most cost-effective treatment (see Table 5). The ICER of tiotropium compared with no treatment group (reference group) was $\$ 1,817.37$ per exacerbation avoided, while the ICER of salmeterol compared with no treatment group was $\$ 2,454.48$ per exacerbation avoided. The strategy of salmeterol is dominated by a blend of no treatment and tiotropium with a coefficient of inequity between 0.138 and $0.177(0.138 \leq \mathrm{k} \leq 0.177)$. The principal of "extended dominance' was used in our incremental cost-effectiveness study to eliminate the strategy (salmeterol) whose costs and effectiveness are improved by a mixed strategy of (tiotropium and no treatment) (Figure 2). Coefficient of inequity is generally applied to demonstrate that only a small proportion of the

Table 4 Base-case analysis for direct cost and effectiveness using Monte Carlo simulations of 100,000 hypothetical patients with moderate COPD

\begin{tabular}{|c|c|c|c|c|c|c|c|c|c|c|}
\hline \multicolumn{6}{|c|}{ Direct cost (\$) } & \multicolumn{5}{|c|}{ Effectiveness (exacerbation avoided/patient/year) } \\
\hline Strategy & Mean & (SD) & Minimum & Median & Maximum & Mean & (SD) & Minimum & Median & Maximum \\
\hline No treatment & 392.1 & $(134.74)$ & 304.405 & 384.405 & 972.995 & 0.69443 & $(0.4376)$ & 0.18875 & 0.56625 & 1.85025 \\
\hline Salmeterol & 1268.66 & $(309.83)$ & 644.815 & 1325.64 & 1919.02 & 1.05156 & $(0.51591)$ & 0.28313 & 0.84938 & 2.13338 \\
\hline Tiotropium & 1408.59 & $(311.79)$ & 696.295 & 1480.08 & 2073.46 & 1.12855 & $(0.4604 \mathrm{I})$ & 0.33975 & 1.01925 & 2.30325 \\
\hline
\end{tabular}

Abbreviation: SD, standard deviation. 
Table 5 Base-case analysis of direct costs, effectiveness, and incremental cost-effectiveness ratios (ICER) of different treatments using Monte Carlo simulation of 100,000 hypothetical patients with moderate COPD

\begin{tabular}{lllll}
\hline Treatment & Direct costs $(\$)$ & $\begin{array}{l}\text { Effectiveness } \\
\text { (exacerbations } \\
\text { avoided/patient/year) }\end{array}$ & $\begin{array}{l}\text { Cost/effectiveness } \\
\text { (\$/exacerbations } \\
\text { avoided/patient/year) }\end{array}$ & $\begin{array}{l}\text { ICER (\$/exacerbations } \\
\text { avoided/patient/year) }\end{array}$ \\
\hline No treatment & 392.1 & 0.694 & 564.636 & 1206.46 \\
Salmeterol & 1268.7 & 1.052 & 1248.14 & 2454.48 \\
Tiotropium & 1408.6 & 1.129 & 1817.37 \\
\hline
\end{tabular}

Notes: Extended dominance report: The strategy 'salmeterol' is dominated by a blend of 'no treatment' group and 'tiotropium' with a coefficient of inequity between 0.138 and 0.1777 .

population would receive an inferior health care strategy if a mixed strategy were used instead of the dominated strategy. ${ }^{29}$ These results indicate that tiotropium is the most cost-effective of the three treatments for patients with moderate COPD. Thus, the ICER for tiotropium indicates that to produce one unit of outcome (exacerbation avoided per patient per year) in patients on tiotropium, an additional $\$ 1,817.37$ cost is incurred compared to the reference group, while to produce the same outcome in patients on salmeterol, an additional cost incurred is $\$ 2,454.48$ compared to the reference group.

\section{Sensitivity analysis}

The base-case estimates were varied over a range (if available from the literature) to study the impact on the final results. In the absence of a range, a $\pm 20 \%$ value of base-case estimates was considered in the analysis. The following variables were subjected to one-way sensitivity analysis: probability of exacerbation, probability of severe exacerbation, probability of hospitalization, and compliance with medications.

The study results were sensitive to changes in compliance rates of treatments. Several cases were seen where tiotropium was dominated by salmeterol when compliance rates were altered. With $100 \%$ compliance in each of the treatment strategies, the direct costs for no treatment, salmeterol and tiotropium were observed to be $\$ 302.2$, $\$ 1,267.9$ and $\$ 1,407.2$, respectively and effectiveness to be $0.883,1.146$, and 1.165 , respectively. The ICER was found to be $\$ 3,327.03$ for salmeterol and $\$ 7,554.64$ for tiotropium group.

Compliance values were then varied $( \pm 20 \%)$ for the different groups. With tiotropium $75 \%$, salmeterol $75 \%$, no treatment 50\% compliance, the ICERs were $\$ 2,451.06$ and $\$ 7,361.94$ for salmeterol and tiotropium, respectively. With tiotropium $90 \%$, salmeterol $50 \%$, no treatment $50 \%$ compliance, the ICERs were $\$ 3,338$ and $\$ 8,213.82$, respectively. With tiotropium $90 \%$, salmeterol $100 \%$, no treatment $50 \%$ compliance, the ICERs were $\$ 1,932.55$ for salmeterol and tiotropium was dominated. With tiotropium 90\%, salmeterol $75 \%$, no treatment $25 \%$ compliance, the ICERs were $\$ 1,940.1$ and $\$ 1,828.86$, respectively. With tiotropium $90 \%$, salmeterol $75 \%$, no treatment $75 \%$ compliance, the ICERs were $\$ 3,324.99$ and $\$ 1,847.11$, respectively. We observe that as the compliance was changed, the ICERs changed drastically (see Figure 3).

\section{Discussion}

The results from the decision modeling analysis indicate that tiotropium is the most cost-effective treatment. From the base-case analysis, the mean costs for the no treatment group were the lowest $(\$ 392.6)$, followed by salmeterol $(\$ 1,268.7)$ and tiotropium $(\$ 1,408.6)$. The mean effectiveness in terms of exacerbations avoided per patient per year for tiotropium, salmeterol, and no treatment were found to be $1.129,1.052$ and 0.694 , respectively. Tiotropium provides more health benefits and is more costly than salmeterol and no treatment. The ICER of tiotropium compared with no treatment was $\$ 1,817.37$ per exacerbation avoided, while the ICER of salmeterol compared with no treatment group was $\$ 2,454.48$ per exacerbation avoided per patient per year. Thus, results demonstrate tiotropium to be more cost-effective than salmeterol and no treatment.

The study was conducted from a payer's perspective since the amount of information in the literature enables only the direct costs involved to be measured. The study was conducted over a 1-year period and would help the payer identify the cost that can be offset by incorporating the most cost-effective treatment strategy. However, given the enormous economic impact of COPD on the society, it would be interesting to see the cost-effectiveness of new treatments from a societal perspective.

The literature search identified 6 cost-effectiveness studies for tiotropium and salmeterol. ${ }^{30-35}$ The results of this study, however, cannot be directly compared to these economic studies, since the methodology, strategies used, and type of study are not exactly the same. All studies indicated that tiotropium 


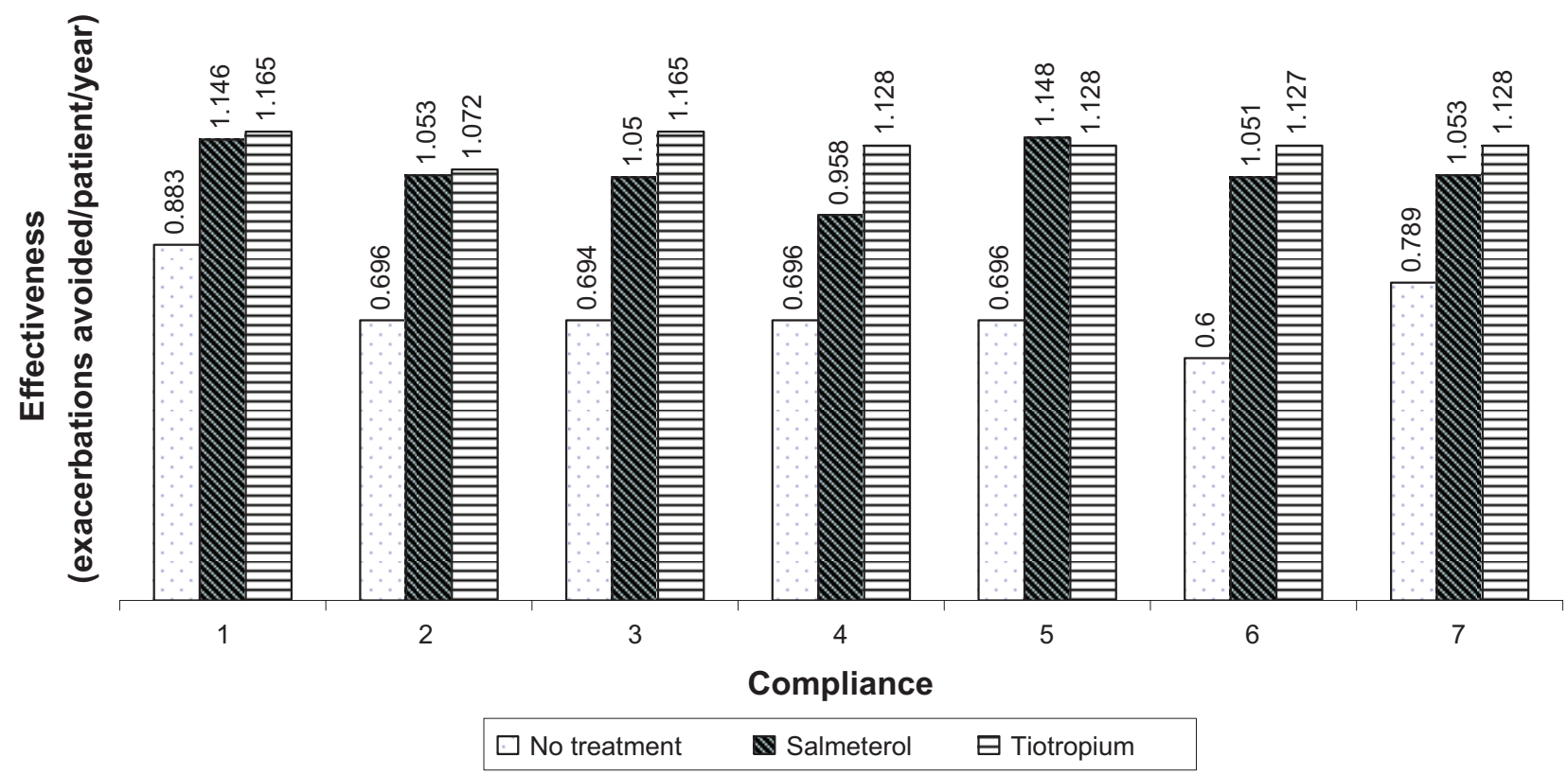

Figure 3 Effect of different drug compliance rates on effectiveness (exacerbations avoided per patient per year).

Notes: I = Tiotropium 100\%, salmeterol 100\%, no treatment 100\% compliance; 2 = Tiotropium $75 \%$, salmeterol $75 \%$, no treatment $50 \%$ compliance; 3 = Tiotropium $100 \%$, salmeterol $75 \%$, no treatment $50 \%$ compliance; 4 =Tiotropium $90 \%$, salmeterol $50 \%$, no treatment $50 \%$ compliance; $5=$ Tiotropium $90 \%$, salmeterol $100 \%$, no treatment $50 \%$ compliance; 6 = Tiotropium $90 \%$,salmeterol $75 \%$, no treatment $25 \%$ compliance; 7 = Tiotropium $90 \%$, salmeterol $75 \%$, no treatment $75 \%$ compliance.

was more cost-effective and also equivalent clinically in terms of effectiveness, which included exacerbations avoided, reduction in hospital admissions, and reduction in overall health care costs. ${ }^{30-35}$

The mean annual cost derived in this study for tiotropium was \$1,408.6. Also, tiotropium showed an effectiveness of 1.129 exacerbations avoided per patient per year. The difference in the effectiveness of tiotropium and salmeterol was found to be 0.077 . In a study by Oostenbrink and colleagues, ${ }^{34}$ the mean difference in the number of exacerbations was 0.17 in favor of tiotropium compared to salmeterol. The costs could not be compared directly since the studies measured costs in euros and this study measured costs in dollars. The results from the study by Maniadakis and colleagues ${ }^{30}$ conducted in Greece demonstrated a mean annual cost per patient of $€ 2,504$ in the tiotropium arm and $€ 2,655$ in the salmeterol arm, indicating tiotropium to be more cost-effective than salmeterol. Also, the study by Lee, ${ }^{35}$ conducted in Singapore indicated a high level of decrease in overall cost per year per patient being treated with tiotropium bromide. Our study findings were in accordance with findings from the studies conducted in Greece and Singapore.

The results from sensitivity analysis showed that there is no significant change in the costs associated with the three treatments and tiotropium was shown to dominate both salmeterol and no treatment. However, the results were sensitive to changes in exacerbation probabilities and also when different compliance rates were included in the study. The analysis was run by varying probability values and compliance rates of all three treatments within a range of $\pm 20 \%$. With a $-20 \%$ change in probability of exacerbation for tiotropium, tiotropium was dominated by salmeterol. In all other cases, tiotropium dominated salmeterol.

The sensitivity analysis for compliance rates shows that the direct cost associated with no treatment is \$392.2, salmeterol \$1,267.3 and tiotropium \$1,407.5. Also, the results indicate that varying compliance values has a significant effect on the ICERs. Thus, compliance is a very important parameter which needs to be addressed and taken into consideration. It would be interesting to see how the costeffectiveness ratios change once more standard and definitive compliance data from clinical studies of each of these treatments become available.

This study has several strengths. The model effectively incorporates the various pathways patients with moderate COPD could undergo. The progression of the tree is in accordance to information obtained from published literature and inputs from expert opinion. This enabled us to create a stable economic model to evaluate the cost-effectiveness of different bronchodilator treatments in moderate COPD. This model is valid clinically and is based on GOLD treatment guideline standards for moderate COPD. The patient population identified in 
this study is clearly defined and only patients with moderate COPD were considered. Although, robust data were available for most key variables, a few variables did not have high-quality estimates. For instance, there is a limited amount of information available in the literature on compliance of patients with tiotropium and salmeterol. In order to tackle this limitation, a series of scenarios using sensitivity analysis was run.

This study has several limitations. The main limitation relates to the availability of data. An ideal data source would be a randomized clinical trial with a large sample size of COPD patients with similar disease severity, comparing all three COPD treatments (tiotropium, salmeterol, and no treatment). In the absence of such a study, data have to be collected from different sources, each having their advantages and limitations. Also, the efficacy data are derived from only 4 published clinical trials. Despite the base-case population in the model being well matched with the clinical trial population; there are generalizability issues with the base-case estimates. Extensive sensitivity analyses were conducted to address this limitation.

There is a dearth of information on the compliance of patients with moderate COPD using bronchodilator medications. This is another major limitation of the study. In this study, different scenarios using sensitivity analysis were tested to see the effect of this important variable on the ICER of different treatments. The different results obtained indicate that compliance is a very important factor which has a strong effect on cost-effectiveness of any treatment strategy. A future study could be designed to capture the compliance rate of COPD patients on tiotropium, salmeterol, and no treatment, and to measure how compliance affects the overall outcomes as well as healthcare costs.

There is an increased need for well designed pharmacoeconomic models as new, specially designed, more effective drugs, biologics and high-cost medications are introduced into the market. In such a scenario, there is a need to identify those medications with the greatest effect on medication costs. This study provides valuable information for payers, policy-makers, and other decision-makers in the formulary review process and for rational clinical decision-making for patients with moderate COPD, until evidence can be accumulated from claims and postmarketing clinical studies. ${ }^{36}$

In current clinical practice, however, different combination treatment strategies are most commonly followed. Combination therapy allows for lower doses and thereby improves safety. Several recent studies have shown better clinical outcomes in the treatment of COPD patients when combination strategies are used. TOwards a Revolution in COPD Health
(TORCH) was a randomized double blind trial, comparing combination therapy with inhaled steroids (ICS - fluticasone) and long-acting 32 -agonists (LABA - salmeterol) with placebo (short-acting bronchodilators on demand), LABA alone or ICS alone for a duration of 3 years. ${ }^{37}$ The primary outcome was all-cause mortality, and the frequency of exacerbations, QoL and rate of decline in $\mathrm{FEV}_{1}$ were also assessed. The combination therapy significantly reduced the annual exacerbation rates from 1.13 to 0.85 , and also improved the health status as well as lung function. Understanding Potential Long-term Impacts on Function with Tiotropium (UPLIFT), a randomized, double-blind trial, compared tiotropium with placebo for 4 years. ${ }^{38}$ Patients were allowed to use all available relevant medications. The primary outcome was the rate of decline in mean $\mathrm{FEV}_{1}$, and secondary outcomes, the frequency of exacerbations, QoL, and mortality, were also assessed. Tiotropium reduced the risk of COPD exacerbations by $14 \%$ (95\% confidence interval) and the risk of respiratory failure by $33 \%$; all-cause mortality during the treatment period was reduced by $16 \%$. Tiotropium also showed improvement in lung function and health status over 4 years, reduced exacerbations, reduced cases of respiratory failure and improved survival.

A study by Calverley et $\mathrm{al}^{39}$ showed that combination therapy with salmeterol and fluticasone improved lung function, symptoms, and health status and reduced use of rescue medication and frequency of exacerbations. Similarly, another study by Mahler et $\mathrm{al}^{40}$ examined the benefits of combining fluticasone propionate with salmeterol to treat the inflammatory and bronchoconstrictive components of COPD. The results of combination treatment strategy improved airflow obstruction, and provided clinical benefits such as reduced severity of dyspnea, reduced use of rescue albuterol, and improved health status.

The Canadian Optimal trial ${ }^{41}$ aimed at identifying whether combining tiotropium with salmeterol or with fluticasone-salmeterol improves the clinical outcomes in moderate to severe COPD compared with tiotropium alone. It was a randomized, double-blind, placebo-controlled trial conducted in 27 academic and community medical centers in Canada over a period of 3 years. The combination treatment strategy with tiotropium plus fluticasone-salmeterol reduced hospitalization rate as well as improved health-related QoL and lung function.

Based on the same study, Najafzadeh et $\mathrm{al}^{42}$ conducted a cost-effectiveness analysis comparing effect on cost on adding salmeterol or fluticasone-salmeterol to tiotropium for COPD. The results indicated an improvement in health outcomes but with an increase in associated costs. Tiotropium, fluticasonesalmeterol and tiotropium-salmeterol combination therapies 
were not found to be economically attractive alternatives to monotherapy with tiotropium.

\section{Conclusions}

COPD is one of the leading causes of morbidity and mortality worldwide and imparts substantial economic burden on society. New treatments are introduced with the goal of optimizing health state of patients. Clinical studies of treatment options suggest that both tiotropium and salmeterol are effective for patients with moderate COPD. The GOLD and ATS guidelines list both treatment options as appropriate for controlling disease. An economic analysis is therefore an appropriate next step to help with decision-making.

However, there is insufficient quantitative economic information available to guide decision-making and treatment selection to minimize the cost effects of this disease. This study evaluated the potential cost-effectiveness of two alternative treatment interventions in patients with moderate COPD. The results will assist private and public payers in evaluating medication choices for effective therapy. The study results demonstrate that use of tiotropium in patients with moderate COPD is more cost effective than salmeterol and no treatment. In context, tiotropium, despite a higher average wholesale price, may be justified as first choice for controlling moderate COPD.

\section{Acknowledgments}

The authors gratefully acknowledge the reviewers of this manuscript for their invaluable comments and suggestions.

\section{Disclosures}

The authors declare no conflicts of interest.

\section{References}

1. National Heart, Lung, and Blood Institute. Morbidity and Mortality: 2009 chart book on cardiovascular, lung, and blood diseases. US Department of Health and Human Services, Public Health Services, National Institutes of Health. http://www.nhlbi.nih.gov/resources/ docs/2009_ChartBook.pdf. Accessed January 2010.

2. Tinkelman D, Corsello P. Chronic obstructive pulmonary disease: the impact occurs earlier than we think. Am J Manag Care. 2003;9: 767-773.

3. Pauwels RA, Buist AS, Calverley PMA, Jenkins CR, Hurd SS. Global Strategy for the Diagnosis, Management, and Prevention of Chronic Obstructive Pulmonary Disease NHLBI/WHO Global Initiative for Chronic Obstructive Lung Disease (GOLD) Workshop Summary Report 2005.

4. Briggs Jr DD. Chronic obstructive pulmonary disease overview: prevalence, pathogenesis, and treatment. J Manag Care Pharm. 2004;10: S3-S10.

5. Tinkelman DG, Price DB, Nordyke RJ, Halbert RJ. Misdiagnosis of COPD and asthma in primary care patients 40 years of age and over. J Asthma. 2006;43:75-80.
6. BR Celli W. MacNee and committee members. Standards for the diagnosis and treatment of patients with COPD: A summary of the ATS/ERS position paper. Eur Respir J. 2004;23:932-946.

7. Mannino DM. COPD: epidemiology, prevalence, morbidity and mortality, and disease heterogeneity. Chest. 2002;121:121S-126S. Cohen BH, Ball Jr WC, Brashears S, et al. Risk factors in chronic obstructive pulmonary disease (COPD). Am J Epidemiol. 1997;105: 223-232.

8. Celli BR. Standards for the optimal management of COPD: a summary Chest. 1998;113:283-287.

9. Ferguson GT. Recommendations for the management of COPD. Chest 2000;117:23S-28S.

10. Barclay L. Tiotropium more effective than salmeterol in COPD. Medscape medical news, Thorax. 2003;58:399-404.

11. Fleming T, editor. Drug Topics Red Book. Montvale, NJ: Thompson PDR; 2006.

12. Claxton AJ, Cramer J, Pierce C. A systematic review of the associations between dose regimens and medication compliance. Clin Ther. 2001;23:1296-310.

13. Cleemput I, Kesteloot K. Economic implications of non-compliance in health care. Lancet. 2002;359:2129-2130.

14. Horwitz RI, Horwitz SM. Adherence to treatment and health outcomes. Arch Inter Med. 1993;153:1863-1868.

15. Vincken W, van Noord JA, Greefhorst APM, et al. Improved health outcomes in patients with COPD during lyear's treatment with tiotropium. Eur Respir J. 2002;19:209-216.

16. Van Noord JA, Bantje TA, Eland ME, Korducki L, Cornelissen PJ. A randomized controlled comparison of tiotropium and ipratropium in the treatment of chronic obstructive pulmonary disease. Thorax. 2000;55:289-294.

17. Tinkelman D, Corsello P, McClure D, Yin M. One-year outcomes from a disease management program for chronic obstructive pulmonary disease. Dis Manag Health Outcomes. 2003;11:49-59.

18. Casaburi R, Mahler DA, Jones PW, et al. A long-term evaluation of once-daily inhaled tiotropium in chronic obstructive pulmonary disease. Eur Respir J. 2002;19:217-224.

19. Rennard SI, Anderson W, Zuwallack R, et al. Use of a Long-acting Inhaled $\beta-2$ Adrenergic Agonist, Salmeterol Xinafoate, in Patients with Chronic Obstructive Pulmonary Disease. Am J Crit Care. 2001;163:1087-1092.

20. Briggs A, Sculpher M. An introduction to Markov modeling for economic evaluation. Pharmacoeconomics. 1993;13:322-338.

21. TreeAge Pro 2005. Users Manual. TreeAge Software, Inc.

22. Donohue JF, van Noord A, Bateman ED, et al. A 6-month, placebocontrolled study comparing lung function and health status changes in COPD Patients treated with tiotropium or salmeterol. Chest. 2002;122:47-55.

23. Kamal K, Miller L, Kavookjjian J, Madhavan S. Alternative decision analysis modeling in the economic evaluation of tumor necrosis factor inhibitors for rheumatoid arthritis. Semin Arthritis Rheum. 2006;36: $50-59$.

24. Naimark D, Krahn MD, Naglie G, Redelmeier DA, Detsky AS. Primer on Medical Decision Analysis: Part 1 - Getting Started. Med Decis Making. 1997;17:123-125.

25. Maximum Allowable Charges. An equal access/equal opportunity university.Available at http://www.purdue.edu/HR/Benefits/mac.htm. Accessed December, 2006.

26. Bradley-Kennedy C, Scalera A, Cramer JA. Treatment persistence and compliance with medications for chronic obstructive pulmonary disease. Can Respir J. 2007;14:25-29.

27. Holt S, Masoli M and Beasley R. Increasing compliance with inhaled corticosteroids through the use of combination therapy. J Allergy Clin Immun. 2004;113:219-220.

28. Cochrane GM, Horne R, Chanez P. Compliance in asthma. Respir Med. 1999;93:763-769.

29. Cantor SB. Cost-effectiveness analysis, extended dominance, and ethics - a quantitative assessment. Med Decis Making. 1994;14:259-265. 
30. Maniadakis N, Tzanakis N, Fragoulakis V, Hatzikou M, Siafakas N. Evaluation of tiotropium and salmeterol in the treatment of chronic obstructive pulmonary disease in Greece. Curr Med Res Opin. 2006;22:1599-1607.

31. Friedman M, Menjoge SS, Anton SF, Kesten S. Healthcare costs with tiotropium plus usual care versus usual care alone following 1 year of treatment in patients with chronic obstructive pulmonary disorder (COPD). Pharmacoeconomics. 2004;22:741-749.

32. Ruiz GA, Fernandez FL, Crespo M. Cost-effectiveness analysis of tiotropium compared to ipratropium and salmeterol. Arch Bronconeumol. 2005;4:242-248.

33. Oostenbrink JB, Van Noord JA, Vincken W. One-year cost-effectiveness of tiotropium versus ipratropium to treat chronic obstructive pulmonary disease. Eur Respir J. 2004;23:241-249.

34. Oostenbrink JB, Molken, Fitzgerald JM. Probabilistic Markov model to assess the cost-effectiveness of bronchodilator therapy in COPD patients in different countries. Value Health. 2005;8:32-46.

35. Lee KH, Phua J, Lim TK. Evaluating the pharmacoeconomic effect of adding tiotropium bromide to the management of chronic obstructive pulmonary disease patients in Singapore. Respir Med. 2006;100: 2190-2196.

36. Watkins JB, Minshall ME, Sullivan SD. Application of economic analyses in US managed care formulary decisions: a private payer's experience. J Manag Care Pharm. 2006;12:726-735.
37. Jones P, Calverley PM, Celli B. The towards a revolution in COPD health (torch) study: fluticasone propionate/salmeterol improves and sustains health status in COPD over 3 years. Chest. 2006;130:177s.

38. Tashkin DP, Bartolome Celli MD, Senn S, et al. A 4-year trial of tiotropium in chronic obstructive pulmonary disease. $N$ Engl J Med. 2008;359:1543-1554.

39. Calverley P, Pauwels R, Vestbo J, et al. Combined salmeterol and fluticasone in the treatment of chronic obstructive pulmonary disease: a randomised controlled trial. Lancet. 2003;361:449-456.

40. Mahler DA, Wire P, Horstman D, et al. Effectiveness of fluticasone propionate and salmeterol combination delivered via the Diskus device in the treatment of chronic obstructive pulmonary disease. Am J Respir Crit Care Med. 2002;166:1084-1091

41. Aaron SD, Vandemheen KL, Fergusson D, et al. Tiotropium in combination with placebo, salmeterol, or fluticasone-salmeterol for treatment of chronic obstructive pulmonary disease: a randomized trial. Ann Intern Med. 2007;146:545-555.

42. Najafzadeh, Marra, Sadatsafavi, Aaron, et al. Cost effectiveness of therapy with combinations of long acting bronchodilators and inhaled steroids for treatment of COPD. Thorax. 2008;63:62-967.
ClinicoEconomics and Outcomes Research

\section{Publish your work in this journal}

ClinicoEconomics \& Outcomes Research is an international, peerreviewed open-access journal focusing on Health Technology Assessment, Pharmacoeconomics and Outcomes Research in the areas of diagnosis, medical devices, and clinical, surgical and pharmacological intervention. The economic impact of health policy and health systems

\section{Dovepress}

organization also constitute important areas of coverage. The manuscript management system is completely online and includes a very quick and fair peer-review system, which is all easy to use. Visit http://www.dovepress.com/testimonials.php to read real quotes from published authors. 